\title{
Adhesion trends and growth mode of ultra-thin copper films on MgO
}

\author{
Yuri F Zhukovskii ${ }^{1,2}$, Eugene A Kotomin ${ }^{1,3,7}$, David Fuks ${ }^{4}$, \\ Simon Dorfman ${ }^{5,8}$, A Marshall Stoneham ${ }^{6}$ and Gunnar Borstel ${ }^{2}$ \\ ${ }^{1}$ Institute for Solid State Physics, University of Latvia, Kengaraga 8, LV-1063 Riga, Latvia \\ ${ }^{2}$ Fachbereich Physik, Universität Osnabrück, Barbarastraße 7, D-49069 Osnabrück, Germany \\ ${ }^{3}$ Max Planck Institut für Festkörperforschung, Heisenbergstraße 1, D-70569 Stuttgart, Germany \\ ${ }^{4}$ Materials Engineering Department, Ben-Gurion University of the Negev, POB 653, Beer-Sheva, \\ Israel \\ ${ }^{5}$ Department of Physics, Israel Institute of Technology-Technion, 32000 Haifa, Israel \\ ${ }^{6}$ Centre for Materials Research, University College London, Gower Street, London WC1E 6BT, \\ UK \\ E-mail: kotomin@fkf.mpg.de
}

Received 2 February 2004

Published 2 July 2004

Online at stacks.iop.org/JPhysCM/16/4881

doi:10.1088/0953-8984/16/28/009

\begin{abstract}
$A b$ initio simulations are performed for $\mathrm{Cu}$ atoms adsorbed on the perfect $\mathrm{MgO}(001)$ substrate, with an ordered metal coverage varied from $\frac{1}{4}$ monolayer (ML), i.e. almost single atoms, up to $1 \mathrm{ML}$. A strong dependence of the adhesion energy and the sub-monolayer film distance from the substrate on the surface coverage and adsorbate positions $\left(\mathrm{Mg}^{2+}\right.$ or $\left.\mathrm{O}^{2-}\right)$ is discussed. The nature of interfacial bonding at all coverages is physisorption. When increasing $\mathrm{Cu}$ atomic fraction, a decrease of the substrate-induced polarization of adatoms accompanied by an increase of both in-plane metallic bonding and the interfacial distance has been found. Combining results of $a b$ initio calculations with thermodynamic theory (taking into account the lattice mismatch), we show that the metal cluster formation becomes the predominant growth mode even at low $\mathrm{Cu}$ coverages, in agreement with experiment.
\end{abstract}

(Some figures in this article are in colour only in the electronic version)

\section{Introduction}

The practical importance of even relatively simple metal/oxide systems, such as copper atoms adsorbed on a $\mathrm{MgO}$ substrate, assumes a variety of guises. In particular, advancing the scientific design of catalysts and coatings is of scientific, environmental and engineering interest [1]. Just

7 Author to whom any correspondence should be addressed.

8 Deceased. 
as the study of systematic trends led, through the image potential model [2], to understanding of the role of substrate properties and of radiation-enhanced adhesion, so should a study of trends with metal coverage give important insights. Although experimental advances now allow fairly in-depth characterization of many adsorbate-surface systems, a comparable level of detailed experimental characterization at heterogeneous interfaces generally remains elusive. Reasons for this discrepancy are clear when one considers the experimental limitations [3].

Stability of the metal-oxide interfaces depends markedly on the adhesion behaviour and on the specific features of the morphology of the interface. A number of theoretical studies were performed for a single $\mathrm{Cu}$ atom and $\mathrm{Cu}$ cluster adhesion on the $\mathrm{MgO}(001)$ surface, most of them based on the embedded and finite cluster model [4-8] which faces well known problems with boundary conditions. There also exist simulations of $\mathrm{Cu}$ clusters on a periodic $\mathrm{MgO}(001)$ slab in the framework of the Car-Parinello approach [9] and plane-wave LDA periodic slab calculations on multilayer $\mathrm{Cu} / \mathrm{MgO}$ interfaces where the $\mathrm{Cu}$ in-plane lattice constant is stretched to that of $\mathrm{MgO}$ [10]. Analysis of numerous $\mathrm{Cu} / \mathrm{MgO}$ interface calculations systemized by Pacchioni et al [6] shows a wide range of obtained adhesion energies $(0.2-$ $1.5 \mathrm{eV})$ and interfacial distances (1.85-2.15 $\AA$ ). This results from use of quite different models (cluster or periodic slabs), basis sets (plane waves or localized orbitals) and methods (varied from Hartree-Fock to DFT with different exchange-correlation functionals). Meanwhile, previous ab initio calculations confirmed that the most attractive sites for the $\mathrm{Cu}$ adhesion on $\mathrm{MgO}(001)$ surface at low coverages are oxygen ions.

In this paper, we report results of the systematic periodic slab calculations of the regular $\mathrm{Cu} / \mathrm{MgO}(001)$ interface, analysing the trends in physical properties as $\mathrm{Cu}$ coverage increases from almost single atom $\left(\frac{1}{4} \mathrm{ML}\right)$ up to $1 \mathrm{ML}$ (figure 1 ). The calculations for different numbers of copper adatoms are performed in the framework of the same formalism, thus allowing us a comprehensive comparative study of the dependence of the adhesion of the sub-monolayer film as a function of metal coverage. A new aspect of broad interest is that the physics of a metal bonding to the $\mathrm{MgO}$ substrate is essentially different for a low coverage and for a monolayer. We also trace back the in-plane changes of a charge redistribution and $\mathrm{Cu}$ density of states properties in sub-monolayer copper films, which is important for understanding the interface conductivity. Our simulations of the interface with successively varied adsorbate concentration are used not only for analysis of the electronic structure changes but also for theoretical prediction of the growth mode for thin metallic film on the insulating substrates, as implemented by us recently [11]. The latter theory combines systematic $a b$ initio calculations on the interface with statistical thermodynamic treatment based on interatomic potentials extracted from the first principles calculations. For the defect-free $\mathrm{Cu} / \mathrm{MgO}(001)$ interface, we show that the formation of well separated metal clusters is practically unavoidable, even at the initial stages of the copper film growth, in agreement with experiment [12].

\section{Theoretical background}

\subsection{First principles calculations}

The periodic DFT calculations have been carried out using the CRYSTAL-98 code [13]. This package uses the localized, LCGTF basis set where each crystalline wavefunction is constructed as a linear combination (LC) of atom-centred Gaussian-type functions (GTFs). In the present study, we use the non-local generalized gradient approximation (GGA) for both exchange and correlation functionals, which have shown earlier very reasonable results in CRYSTAL-DFT calculations on the metal adhesion on the metal oxide interfaces [14]. The most appropriate description of the regular $\mathrm{Cu} / \mathrm{MgO}(001)$ interface is achieved using Becke's non-local, hybrid (DFT-HF), three-parameter exchange-correlation functional B3LYP [15]. 
(a)

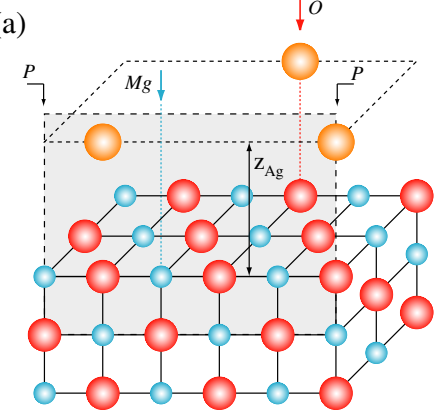

(c)

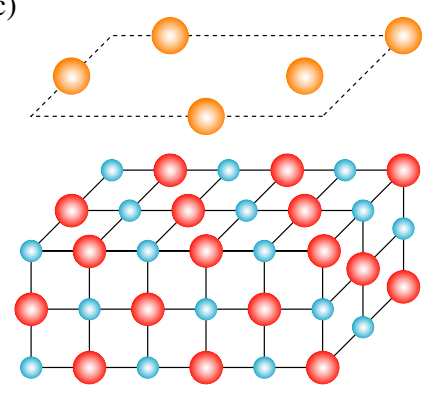

(e)

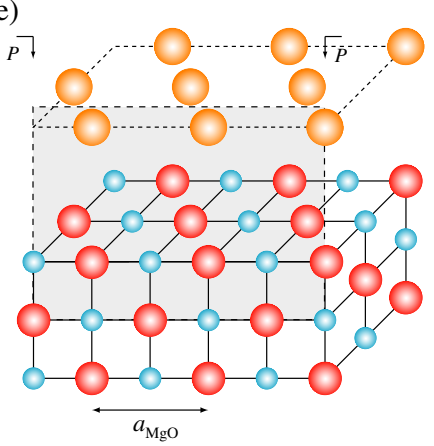

(b)

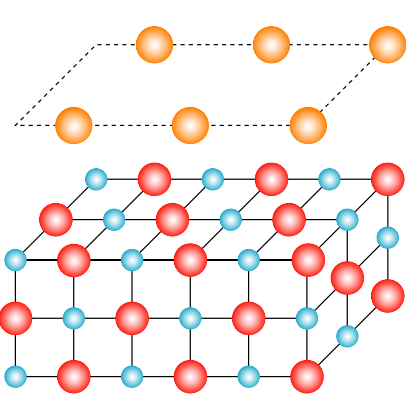

(d)

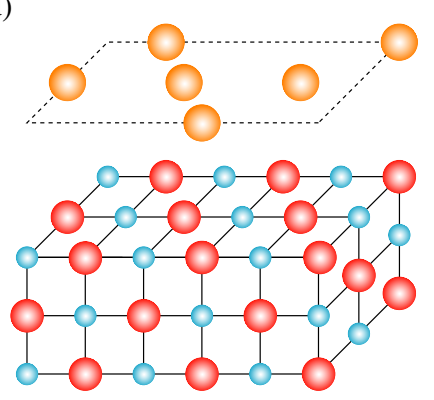

Figure 1. Fragments of the regular $\mathrm{Cu} / \mathrm{MgO}(001)$ interface with $\frac{1}{4} \mathrm{ML}$ (a), regular (net) and striped $\frac{1}{2} \mathrm{ML}$ (b) and (c), $\frac{3}{4} \mathrm{ML}(\mathrm{d})$, and $1 \mathrm{ML}$ (e) coverages where $\mathrm{Cu}$ atoms lie in a plane at the distance $z_{\mathrm{Cu}}$ above surface $\mathrm{O}^{2-}$ ions. (a) and (e) show the cross-sections used for electron density plots (figure 3). The adsorption patterns atop the surface $\mathrm{Mg}^{2+}$ ions are not shown.

Another crucial point in CRYSTAL calculations is a correct choice of the basis sets (BSs) used in GTFs. The all-valence BSs for MgO optimized earlier for the CRYSTAL calculations (8s-511sp and 8s-411sp for magnesium and oxygen, respectively) [16] were found to be suitable for the present simulations, and we only slightly re-optimized the outermost shells for $\mathrm{Mg}$ and $\mathrm{O}$. As a result, we could achieve for bulk $\mathrm{MgO}$ a good agreement with the corresponding experimental values for the calculated lattice constant and bulk modulus, as well as band structure in the most important HOMO-LUMO energy range (table 1) [17, 18]. However, we have re-optimized considerably the all-valence $\mathrm{Cu}$ BS developed elsewhere for describing copper interaction with chlorine [19], since this $\mathrm{BS}$ is not well suited for the $\mathrm{Cu} / \mathrm{MgO}(001)$ 
Table 1. Some cohesive and electronic properties of $\mathrm{Cu}$ and $\mathrm{MgO}$ crystals (lattice constant $a_{0}$, bulk modulus $B$, cohesion energy per atom $E_{\mathrm{coh}}$, width of the $\mathrm{Cu}$ conduction band $\Delta \varepsilon_{\mathrm{Cu}}^{\mathrm{CB}}$ as well as widths of $\mathrm{MgO}$ energy gap at different points of Brillouin zone: $\Delta \varepsilon_{\mathrm{MgO}}^{\Gamma}, \Delta \varepsilon_{\mathrm{MgO}}^{\mathrm{L}}$ and $\Delta \varepsilon_{\mathrm{MgO}}^{\mathrm{X}}$ ) calculated using the B3LYP method for a verification of the GTF basis sets and their comparison with available experimental and theoretical data.

\begin{tabular}{lllllllll}
\hline \multirow{2}{*}{ Crystal } & $\begin{array}{l}\text { Source } \\
\text { of data }\end{array}$ & $\begin{array}{l}a_{0}{ }^{\mathrm{a}} \\
(\AA)\end{array}$ & $\begin{array}{l}B^{\mathrm{b}} \\
(\mathrm{GPa})\end{array}$ & $\begin{array}{l}E_{\mathrm{coh}} \\
(\mathrm{eV})\end{array}$ & $\begin{array}{l}\Delta \varepsilon_{\mathrm{Cu}}^{\mathrm{CB}} \\
(\mathrm{eV})\end{array}$ & $\begin{array}{l}\Delta \varepsilon_{\mathrm{MgO}}^{\Gamma}{ }^{\mathrm{c}} \\
(\mathrm{eV})\end{array}$ & $\begin{array}{l}\Delta \varepsilon_{\mathrm{MgO}}^{\mathrm{L}}{ }^{\mathrm{c}} \\
(\mathrm{eV})\end{array}$ & $\begin{array}{l}\Delta \varepsilon_{\mathrm{MgO}}^{\mathrm{X}}{ }^{\mathrm{c}} \\
(\mathrm{eV})\end{array}$ \\
\hline \multirow{2}{*}{$\mathrm{Cu} \quad$} & Our study & 3.68 & 131 & 3.25 & 9.4 & - & - & - \\
& Experiment & $3.61^{\mathrm{d}}$ & $138^{\mathrm{d}}$ & $3.51^{\mathrm{d}}$ & $8.6 \pm 0.4^{\mathrm{e}}$ & - & - & - \\
& Other calculations & $3.63^{\mathrm{f}}$ & $155^{\mathrm{f}}$ & $3.89^{\mathrm{f}}$ & $9.3^{\mathrm{e}}$ & - & - & - \\
& Our study & 4.24 & $138^{\mathrm{MgO}}$ & - & - & 6.9 & 12.8 & 14.7 \\
& Experiment & $4.21^{\mathrm{g}}$ & $155^{\mathrm{g}}$ & - & - & $7.7^{\mathrm{h}}$ & $10.8^{\mathrm{h}}$ & $13.3^{\mathrm{h}}$ \\
& Other calculations & $4.13^{\mathrm{g}}$ & $156^{\mathrm{g}}$ & - & - & $8.2^{\mathrm{g}}$ & $12.5^{\mathrm{g}}$ & $14.3^{\mathrm{g}}$ \\
\hline
\end{tabular}

a Calculation error is estimated to be $0.05 \AA$.

b The estimated error is $\approx 5 \mathrm{GPa} ; 1 \mathrm{GPa}=2.29371 \times 10^{-4}$ Hartree $\AA^{-3}=1 \mathrm{GJ} \mathrm{m}^{-3}=10^{-2} \mathrm{Mbar}$.

c The estimated error is $0.1 \mathrm{eV}$.

${ }^{\mathrm{d}}$ Reference [26] (experimental values were obtained in the temperature interval 273-298 K).

e Reference [25].

${ }^{\mathrm{f}}$ Reference [19] (DFT-GGA GTF calculations).

g Reference [17] (DFT plane wave calculations).

${ }^{\mathrm{h}}$ Reference [18].

interface [20]. We have chosen a small Hay-Wadt pseudopotential [21] for the core of the $\mathrm{Cu}$ atom (this procedure was quite successful in our previous $\mathrm{Ag} / \mathrm{MgO}(001) \mathrm{CRYSTAL}$ calculations [22]) and carefully re-optimized coefficients and exponents of sub-valence, valence and virtual shells (4111sp-41d GTF), in order to get the minimum of total energy per $\mathrm{Cu}$ atom. Optimization of basis sets has been performed using ParOptimize code [23] interfaced with CRYSTAL-98 [13]. It implements the conjugated gradient optimization technique [24] with numerical computation of derivatives. With the re-optimized BS, the copper properties are described as well as by other well known first principles simulations [19, 25, 26], providing a good agreement with experimental values of the lattice constant, bulk modulus and cohesion energy [26] as well as different parameters of band structure for $\mathrm{Cu}$ bulk including the width of the conduction band [25] (table 1). We have also calculated several properties for pure $\mathrm{Cu}(001)$ slabs; in particular, the surface energy for a five-layer defect-free slab of $1540 \mathrm{erg} \mathrm{cm}^{-2}$ was found to be in a quite good qualitative agreement with the experimental value of $1790 \mathrm{erg} \mathrm{cm}^{-2}$ obtained for the polycrystalline sample [26].

\subsection{Slab model}

For the perfect $\mathrm{MgO}(001)$ substrate, we have used the 2D three-layer slab (figure 1). The choice of this model was justified by a comparison of the results of our previous calculations on three-, five- and seven-layer magnesia slabs with one- and two-sided metal coverages [27]. Since results were quite close, we have chosen the model which needs smaller computational resources and thus permits us to focus on a more careful structural optimization. Because the one-side ordered coverage of the magnesia slab by copper atoms was varied from $\frac{1}{4} \mathrm{ML}$ to $1 \mathrm{ML}$, we performed the calculations for a $2 \times 2$ extended $\mathrm{MgO}(001)$ surface unit cell. For all five structures we optimized the total energy, as a function of the substrate lattice constant $a_{\mathrm{MgO}}$ and the distance $z_{\mathrm{Cu}}$ between the 2D lattice of $\mathrm{Cu}$ atoms and an underlying $\mathrm{MgO}$ slab. In this optimization, we have found negligible magnesia surface relaxation, which agrees with earlier studies [28]. 
The quality of the results of our interfacial slab calculations based on the re-optimized BS is quite good as follows from the discussion below and a comparison with the results of recent experimental studies [29-31]. The $15 \%$ mismatch of $\mathrm{Cu}$ and $\mathrm{MgO}$ lattice constants results in a strain in a metal film. However, this is not relevant for the adsorption of single, pseudo-isolated $\mathrm{Cu}$ atoms. Therefore, use of $\frac{1}{4} \mathrm{ML}$ (figure 1 (a)) and particularly regular $\frac{1}{2}$ ML coverage, where $\mathrm{Cu}$ atoms are not the nearest neighbours (figure $1(\mathrm{~b})$ ), on the perfect $\mathrm{MgO}(001)$ surface is quite justified for a simulation of the interaction between $\mathrm{Cu}$ atom and oxide substrate. We have also simulated three more strained adsorbate configurations: striped $\frac{1}{2} \mathrm{ML}$ (figure $1(\mathrm{c})$ ), $\frac{3}{4} \mathrm{ML}$ (figure 1(d)) and 1 ML (figure 1(e)), which are used for our analysis of the trend in the $\mathrm{Cu} / \mathrm{MgO}$ bonding as metal atom concentration increases, and for thermodynamic analysis of the growth mode (where these interfacial patterns serve as the reference structures and should not necessarily be equilibrium).

\subsection{Thermodynamic method}

The choice of five ordered interfacial structures shown in figure 1 is neither an accidental nor an arbitrary one; their energetics is required for the statistical method [11] developed by us to study thermodynamics and morphology of thin metallic film growth on ceramic substrate at different temperatures based on the first principles calculations at $0 \mathrm{~K}$. Copper film is formed on the planar lattice placed above the $\mathrm{MgO}(001)$ substrate. The sites of such a lattice are placed above the surface oxygen ions, which are preferable for copper adhesion. The $\mathrm{Cu}$ atom lattice is immersed in the field of the electronic charge distribution created by the magnesia surface. One can treat the $\mathrm{Cu}$ film in terms of the 2D 'solid solution' $\mathrm{Cu}-\mathrm{E}$, i.e. $\mathrm{Cu}$ - 'empty sites' occupied by quasi-particles, E. The thermodynamics of such a solid solution may be formulated with the help of the effective mixing potential

$$
\tilde{V}\left(\mathbf{r}, \mathbf{r}^{\prime}\right)=V_{\mathrm{Cu}-\mathrm{Cu}}\left(\mathbf{r}, \mathbf{r}^{\prime}\right)+V_{\mathrm{E}-\mathrm{E}}\left(\mathbf{r}, \mathbf{r}^{\prime}\right)-2 V_{\mathrm{Cu}-\mathrm{E}}\left(\mathbf{r}, \mathbf{r}^{\prime}\right),
$$

where $V_{\mathrm{Cu}-\mathrm{Cu}}\left(\mathbf{r}, \mathbf{r}^{\prime}\right), V_{\mathrm{E}-\mathrm{E}}\left(\mathbf{r}, \mathbf{r}^{\prime}\right)$ and $V_{\mathrm{Cu}-\mathrm{E}}\left(\mathbf{r}, \mathbf{r}^{\prime}\right)$ are the effective interatomic potentials between copper atoms, between quasi-particles and between copper atoms and quasi-particles, respectively; $\mathbf{r}$ and $\mathbf{r}^{\prime}$ are the positions of the sites in 2D lattice. Actually, this mixing potential reflects the interaction in such a 2D system embedded into the field of the half-infinite $\mathrm{MgO}$ restricted by a free (001) surface. It is possible to determine the atomic fraction of $\mathrm{Cu}$ atoms or of E-quasi-particles in this 2D solution in a usual way. The problem of thermodynamic stability of this 2D solid solution transforms to a study of the ordering and/or decomposition tendencies in such a binary system on the 2D Ising lattice and may be considered in terms of the phase diagram of a 2D alloy, in the framework of the concentration wave (CW) approach [32].

The distribution of atoms A in a binary alloy using this approach is described by a single occupation probability function $n(\mathbf{r})$. This function gives the probability to find the atom A $(\mathrm{Cu})$ at the site $\mathbf{r}$ of the crystal lattice. The configurational part of the free energy of formation of the $2 \mathrm{D}$ solid solution per atom is given by

$F=\frac{1}{2 N} \sum_{\substack{\mathbf{r}, \mathbf{r}^{\prime} \\ \mathbf{r} \neq \mathbf{r}^{\prime}}} \tilde{V}\left(\mathbf{r}, \mathbf{r}^{\prime}\right) n(\mathbf{r}) n\left(\mathbf{r}^{\prime}\right)+k T \sum_{\mathbf{r}}\{n(\mathbf{r}) \cdot \ln n(\mathbf{r})+[1-n(\mathbf{r})] \cdot \ln [1-n(\mathbf{r})]\}$.

Here $T$ is temperature, $k$ the Boltzmann constant and $n(\mathbf{r})$ determines a distribution of solute atoms in an ordering phase. The summation is performed over the sites of the $2 \mathrm{D}$ Ising lattice.

To simulate the coating of substrate by $\mathrm{Cu}$ atoms, we have chosen nearly the same $2 \mathrm{D}$ reference structures for the occupation probability functions as described for $\mathrm{Ag} / \mathrm{MgO}(001)$ earlier [11]. (Additionally, we have considered here the structure with $\frac{3}{4}$ ML coverage.) For a $\frac{1}{2}$ 'net' ML this is $n_{1}(\mathbf{r})=c_{A}^{(1)}+0.5 \eta \cdot \mathrm{e}^{2 \pi \mathrm{i} x}$ and for a $\frac{1}{2}$ 'striped' $\operatorname{ML} n_{2}(\mathbf{r})=c_{A}^{(2)}+0.5 \eta \cdot \mathrm{e}^{\pi \mathrm{i}(x+y)}$, 
Table 2. Parameters of the $\mathrm{Cu} / \mathrm{MgO}(001)$ interface obtained in our calculations and their comparison with previous periodic slab calculations.

\begin{tabular}{|c|c|c|c|c|c|}
\hline $\begin{array}{l}\mathrm{Cu} \text { atom } \\
\text { over }\end{array}$ & $\begin{array}{l}\text { Substrate } \\
\text { coverage }\end{array}$ & & $\begin{array}{l}\text { Distance to } \\
\mathrm{MgO} \text { surface }^{\mathrm{a}} \\
z_{\mathrm{Cu}}^{(\mathrm{o})}(\AA)\end{array}$ & $\begin{array}{l}\text { Adhesion } \\
\text { energy per } \mathrm{Cu}^{\mathrm{b}} \\
E_{\text {adh }}(\mathrm{eV})\end{array}$ & $\begin{array}{l}\text { Charge } \\
\text { transfer } \\
\Delta q_{\mathrm{Cu}}{ }^{\mathrm{c}}(e)\end{array}$ \\
\hline \multirow[t]{7}{*}{$\mathrm{O}^{2-}$ ion } & \multirow{2}{*}{\multicolumn{2}{|c|}{$\frac{1}{4} \mathrm{ML}$}} & 2.08 & 0.62 & 0.047 \\
\hline & & & $1.9^{\mathrm{d}}$ & $1.4^{\mathrm{d}}$ & $0.03^{\mathrm{d}}$ \\
\hline & \multirow{2}{*}{$\frac{1}{2} \mathrm{ML}$} & \multirow{5}{*}{$\begin{array}{l}\text { Regular } \\
\text { Striped }\end{array}$} & 2.11 & 0.65 & 0.018 \\
\hline & & & 2.25 & 0.37 & 0.003 \\
\hline & $\frac{3}{4} \mathrm{ML}$ & & $2.21 / 2.38^{\mathrm{f}}$ & $0.34 / 0.32^{\mathrm{f}}$ & $0.002 /-0.006^{\mathrm{f}}$ \\
\hline & & & 2.36 & 0.33 & -0.007 \\
\hline & & & $2.0^{\mathrm{e}}$ & $1.0^{\mathrm{e}}$ & $-0.08^{\mathrm{e}}$ \\
\hline \multirow[t]{7}{*}{$\mathrm{Mg}^{2+}$ ion } & \multirow{2}{*}{$\frac{1}{4} \mathrm{ML}$} & \multirow{7}{*}{$\begin{array}{l}\text { Regular } \\
\text { Striped }\end{array}$} & 2.63 & 0.48 & -0.027 \\
\hline & & & $2.5^{\mathrm{d}}$ & $0.5^{\mathrm{d}}$ & - \\
\hline & \multirow{2}{*}{$\frac{1}{2} \mathrm{ML}$} & & $2.38 / 2.68^{f}$ & $0.42 / 0.38^{\mathrm{f}}$ & $-0.016 /-0.022^{f}$ \\
\hline & & & 2.78 & 0.26 & -0.014 \\
\hline & $\frac{3}{4} \mathrm{ML}$ & & 2.87 & 0.20 & -0.013 \\
\hline & \multirow{2}{*}{$1 \mathrm{ML}$} & & 2.98 & 0.13 & -0.003 \\
\hline & & & $3.20^{\mathrm{e}}$ & $0.2^{\mathrm{e}}$ & $-0.06^{\mathrm{e}}$ \\
\hline
\end{tabular}

a The estimated error is $0.05 \AA$.

$\mathrm{b}$ The basis set superposition error is $\approx 0.1 \mathrm{eV}$.

$\mathrm{c}$ The estimated error is $0.05 e$; a positive sign means an excess of the electron charge as compared to a neutral atom.

${ }^{\mathrm{d}}$ Reference [5] (cluster calculations).

e Reference [10] (slab calculations).

${ }^{\mathrm{f}}$ For two local minima.

whereas the occupation function for $\frac{1}{4}$ ML is extended now for the case of $\frac{3}{4}$ ML using a modified definition:

$$
n_{3}(\mathbf{r})=c_{A}^{(3)}+\gamma \eta_{1} \mathrm{e}^{2 \pi \mathrm{i} x}+\gamma \eta_{2}\left[\mathrm{e}^{\pi \mathrm{i}(y+x)}+\mathrm{e}^{\pi \mathrm{i}(y-x)}\right],
$$

where $x$ and $y$ are the coordinates of the lattice sites of the Ising lattice, in the lattice parameter units. The stoichiometric compositions of these ordered $2 \mathrm{D}$ phases are $c_{A}^{(1)}=c_{A}^{(2)}=\frac{1}{2}, c_{A}^{(3)}=$ $\frac{1}{4}$ or $\frac{3}{4}$ for $\gamma=\frac{1}{4}$ or $-\frac{1}{4}$, respectively. It is easy to check by a direct substitution of coordinates of the Ising lattice sites that for these structures in the ordered states and stoichiometric compositions the occupation probabilities are equal to unity in the sites occupied by $\mathrm{Cu}$ atoms and are equal to zero in the empty sites. The internal formation energies for these phases $\left(U_{1}, U_{2}\right.$ and $\left.U_{3}\right)$ were defined previously [11], via Fourier transforms of the mixing potential described in equation (1) as well as the long-range order parameters $\eta, \eta_{1}$ and $\eta_{2}$ which are also equal to unity for the ordered phases and are zero for the absolutely disordered state. The total energies of the ordered superstructures are calculated using the B3LYP method (see section 2.1).

\section{Ab initio simulation of the ordered interface patterns}

For all calculated adsorbate structures, we found that the equilibrium value of $a_{\mathrm{MgO}}$ is practically the same, while $z_{\mathrm{Cu}}$ considerably changes (table 2). Figure 2 shows the binding interfacial energy $E_{\mathrm{b}}$ versus $z_{\mathrm{Cu}}$ for different $\mathrm{Cu}$ coverages over both $\mathrm{Mg}^{2+}$ and $\mathrm{O}^{2-}$ ions whereas table 2 presents the equilibrium $z_{\mathrm{Cu}}$ values, the adhesion energy and effective atomic charges on adatoms for all considered configurations. We observe a marked difference in adhesion energies 


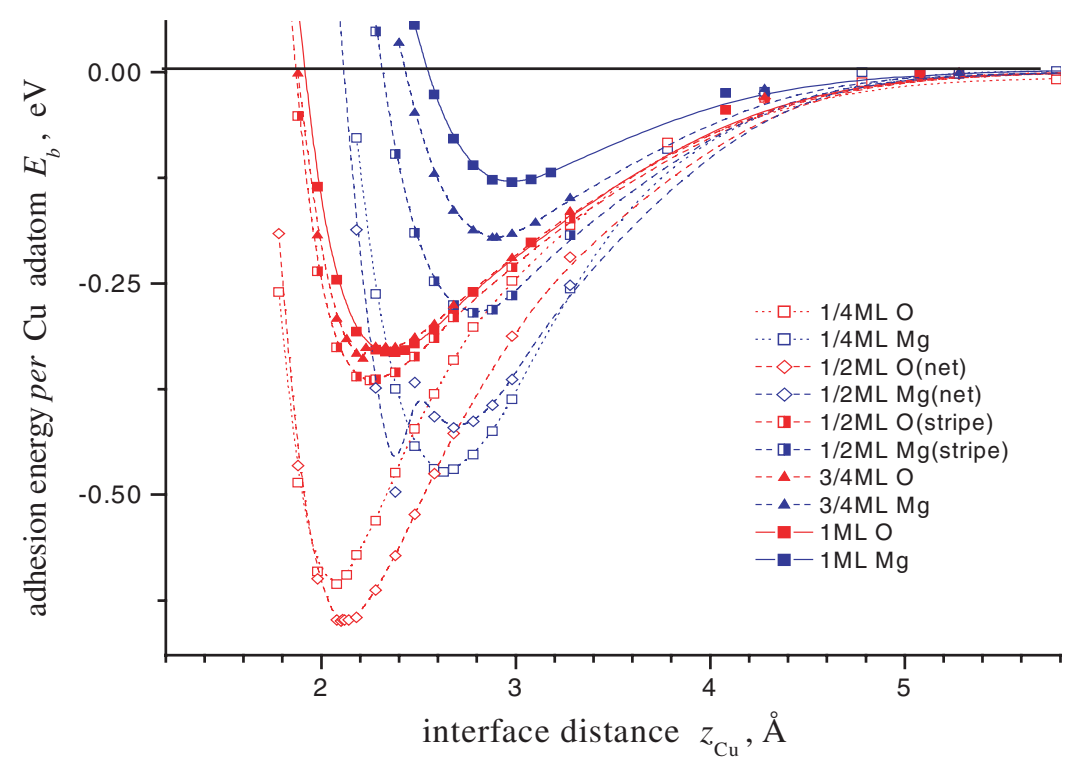

Figure 2. The adhesion energy $E_{\mathrm{b}}$ as a function of $z_{\mathrm{Cu}}$ for two different adsorption sites, $\mathrm{Mg}^{2+}$ and $\mathrm{O}^{2-}$ (figure 1 ), and five differently ordered Cu coverages, $\frac{1}{4} \mathrm{ML}, \frac{1}{2} \mathrm{ML}$ (net and stripe distributions), $\frac{3}{4} \mathrm{ML}$ and $1 \mathrm{ML}$, on the $\mathrm{MgO}(001)$ substrate.

for a low $\mathrm{Cu}$ coverage, when adatoms are placed over surface $\mathrm{Mg}^{2+}$ or $\mathrm{O}^{2-}$ ions: the relevant adsorption energy over magnesium ions is smaller by $30 \%$ than that over oxygen ions, which is accompanied by a substantial increase of the interfacial distance. As Cu coverage increases from $\frac{1}{4}$ to $\frac{1}{2}$ (a regular distribution), the adhesion energy for $\mathrm{Cu}$ atoms over $\mathrm{O}^{2-}$ ions increases to $0.65 \mathrm{eV}$ (table 2 and figure 2). This can be explained by an additional interaction for $\frac{1}{2} \mathrm{ML}$ between $\mathrm{Mg}^{2+}$ ions and an excessive electron density concentrated in the interstitial positions between $\mathrm{Cu}$ atoms. We also found that the adsorption of $\mathrm{Cu}$ atop both surface $\mathrm{O}^{2-}$ ions for a $\frac{3}{4} \mathrm{ML}$ and $\mathrm{Mg}^{2+}$ ions for a $\frac{1}{2}$ net ML results in an unusual two local minima on the energy curves versus $z_{\mathrm{Cu}}$ (figure 2). These arise due to a delicate interplay of the different spin states: the energy minimum closest to the surface corresponds to the triplet spin state whereas another minimum belongs to the singlet spin state. The existence of the two local minima on the adhesion curve reflects the complicated nature of the $\mathrm{Cu}$ polarization: the minimum closest to the surface is characterized by the substantial $\mathrm{Cu}$ electronic charge repulsion from the surface, i.e. the $\mathrm{Cu}$ atom becomes a highly polarized dipole, whereas another minimum is caused by the quadrupole interactions of this atom with the surface.

When passing to the $\frac{1}{2}$ ML striped configuration, $\frac{3}{4}$ ML and $1 \mathrm{ML}$, the adhesion energy of $\mathrm{Cu}$ over $\mathrm{O}^{2-}$ ions becomes sufficiently smaller, $0.37,0.34$ and $0.33 \mathrm{eV}$, respectively. This is very likely result of a stress and/or specific features of the electron charge density redistribution in an artificially expanded metal 'stripe' or monolayer. The relevant interface distances considerably exceed those for a regular $\frac{1}{2} \mathrm{ML}$ and $\frac{1}{4} \mathrm{ML}$ (table 2). This is well correlated with the recent $\mathrm{x}$-ray absorption measurements [29], which show that the interfacial distance $z_{\mathrm{Cu}-\mathrm{O}^{2-}}$ should be larger than the analogous distance in the copper oxide bulk (1.88-1.97 $\AA$ ) but smaller than the nearest-neighbour distance in the $\mathrm{Cu}$ bulk $(2.55 \AA)$. In a line with this, as copper coverage increases, our equilibrium distance for a pseudo-isolated adatom $(\approx 2.1 \AA$ ) increases as well (to 2.2-2.3 $\AA$ ), becoming closer to the interatomic distances in the copper aggregates. Recently, using microcalorimetry [31], an initial heat of $\mathrm{Cu}$ adhesion on the $\mathrm{MgO}(001)$ substrate was 
(a)

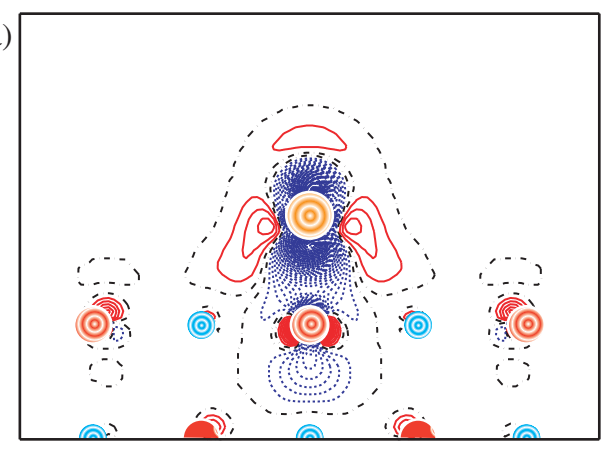

(b)

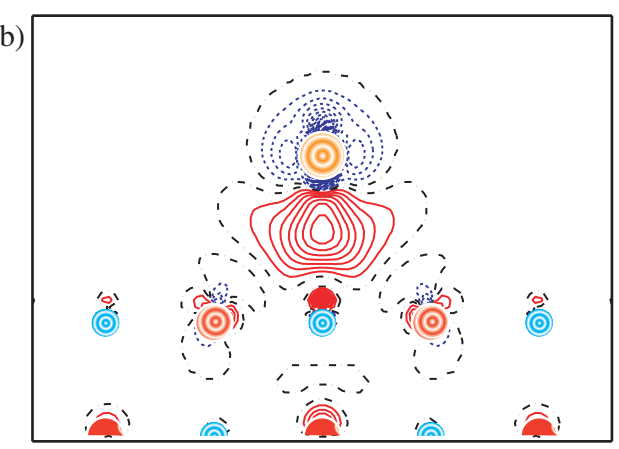

() $\mathrm{Cu}$ (ㅇ $\mathrm{O}^{2-}$ () $\mathrm{Mg}^{2+} \vdots$

(c)

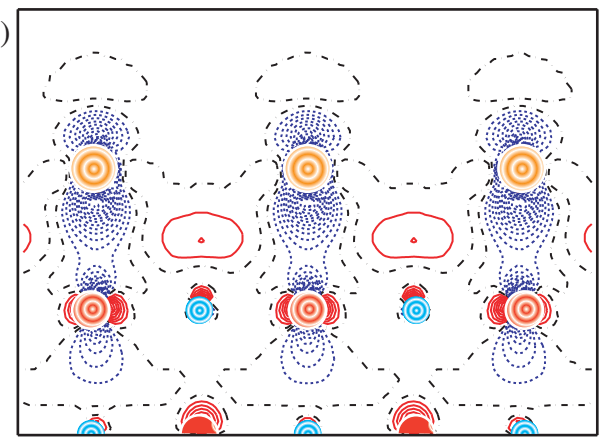

(d)

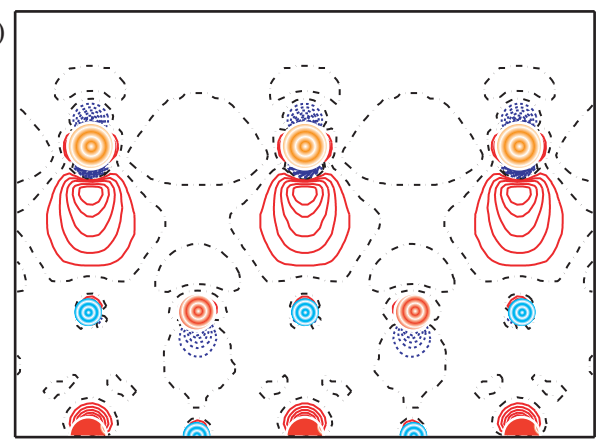

Figure 3. The difference electron density maps $\Delta \rho(\mathbf{r})$ (the total density minus a superposition of the densities for the isolated $\mathrm{Cu}$ and $\mathrm{MgO}$ slabs) in the cross-section perpendicular to the (001) interface plane (figures 1(a), (e)) for two different copper coverages: (a) $\frac{1}{4} \mathrm{Cu} M L$ over a $\mathrm{O}^{2-}$ surface ion; (b) $\frac{1}{4} \mathrm{Cu}$ ML over a $\mathrm{Mg}^{2+}$ surface ion; (c) $1 \mathrm{ML}$ over a $\mathrm{O}^{2-}$; (d) $1 \mathrm{ML}$ over a $\mathrm{Mg}^{2+}$. Isodensity curves are drawn from -0.05 to $+0.05 e \mathrm{au}^{-3}$ with increments of $0.001 e \mathrm{au}^{-3}$. The full, dashed and chained curves show positive, negative and zero difference electron densities, respectively.

estimated to be as large as $2.4 \mathrm{eV}$ per adatom, which is much larger than our or any other theoretical prediction for the $\mathrm{Cu}$ binding energy. Although this thermodynamic parameter is not the same as an adsorption energy, the discrepancy is too large and we suppose that it is a trapping of mobile $\mathrm{Cu}$ atoms at surface defects which very likely causes such a large heat of adhesion. (An important role of surface defects in the enhanced $\mathrm{Cu}$ bonding on the $\mathrm{MgO}(001)$ substrate was also observed experimentally [12].) Thus we believe that our prediction for $\mathrm{Cu}$ binding energy on the perfect $\mathrm{MgO}(001)$ surface $(0.6-0.8 \mathrm{eV}$ per adatom) is correct.

The calculated Mulliken charges on $\mathrm{Cu}$ atoms indicate either a negligible charge transfer towards adatoms from surface $\mathrm{O}^{2-}$ ions for $\frac{1}{4}$ and $\frac{1}{2} \mathrm{ML}$ coverages, or very small charge donation towards a substrate for other interfacial configurations (table 1). However, the latter is within the limits of the accuracy of the Mulliken population analysis $(\approx 0.05 e)$. Meanwhile, the bond populations between metal atoms and substrate ions across the interface are practically zero. The electron charge re-distribution in several interface patterns shown in figure 3 gives the most convincing argument in favour of a decisive role of the electrostatic interaction between polarized $\mathrm{Cu}$ atoms and surface $\mathrm{O}^{2-}$ ions as the physisorption mechanism of $\mathrm{Cu}$ thin film adhesion on the perfect $\mathrm{MgO}(001)$ substrate. A comparison of the electron density 


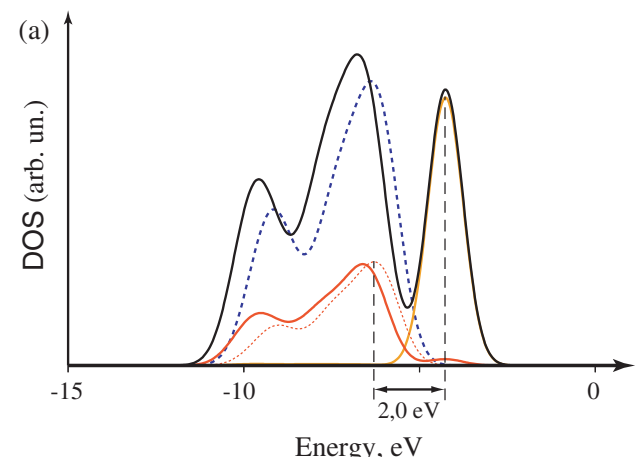

Energy, eV

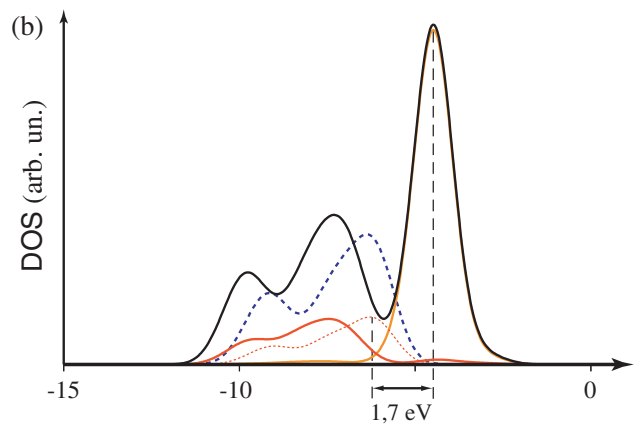

Energy, eV

Total DOS

PDOS of interfacial O $(2 p)$

PDOS of interfacial $\mathrm{Cu}(3 d)$

Total DOS for pure $\mathrm{MgO}$ slab

PDOS of interfacial $\mathrm{O}(2 p)$ for pure $\mathrm{MgO}$ slab

Figure 4. Total and projected DOS for the two different $\mathrm{Cu}$ substrate coverages: $\frac{1}{4}$ ML (figure 1(a)) and $1 \mathrm{ML}$ (figure 1(e)). The largest peaks were normalized to the same value whereas a convolution of individual energy levels was plotted using the Gaussians with a half-width of $0.8 \mathrm{eV}$.

plots for $\frac{1}{4}$ ML in figures 3(a) and (b) indicates that single $\mathrm{Cu}$ atoms are more distorted above surface $\mathrm{O}^{2-}$ ions (where the charge transfer from the substrate is also greater) rather than above $\mathrm{Mg}$ ions. The same is true for a noticeable polarization of both nearest and nextnearest surface $\mathrm{O}^{2-}$ ions, while electronic shells of $\mathrm{Mg}^{2+}$ ions are not affected too much by $\mathrm{Cu}$ adatoms. The contribution of the subsurface substrate ions to the bonding of copper adatoms is also negligible. As the $\mathrm{Cu}$ coverage grows, the electron density re-distribution for $1 \mathrm{ML}$ (figures 3(c) and (d)) clearly demonstrates the appearance of an additional extra charge density concentrated in hollow positions between $\mathrm{Cu}$ atoms. For the $\mathrm{Cu}$ adsorption above surface $\mathrm{O}^{2-}$ ions, this extra charge has an attractive interaction with the surface $\mathrm{Mg}^{2+}$ ions below it, whereas for an alternative $1 \mathrm{ML}$ interface (figure 3(d)), in contrast, a repulsion occurs between the $\mathrm{Cu}$ interatomic density and surface oxygen ions. At $1 \mathrm{ML}$, we have also observed a noticeable bond population between nearest $\mathrm{Cu}$ atoms $(0.075 e$ per atom) within the metal plane, which is not sensitive to the particular adsorption site. These peculiarities of the electronic structure can lead to substantial changes in conducting properties that could be important for microelectronic applications.

Analysis of the density of states (DOS) for the Cu layer (see figure 4) confirms substantial changes in conductive electron distributions for different $\mathrm{Cu}$ coverages. The oxygen states $\mathrm{O}(2 \mathrm{p})$ are very sensitive to the change of metal coverage. For net-type coatings $\left(\frac{1}{4} \mathrm{ML}\right.$ and $\frac{1}{2} \mathrm{ML}$ ), we observe a pseudo-gap (the energy difference between the magnesia $\mathrm{O}(2 \mathrm{p})$ and $\mathrm{Cu}(3 \mathrm{~d})$ peaks). Obviously, the largest pseudo-gap occurs for the $\frac{1}{4} \mathrm{Cu} \mathrm{ML}$ (figure 4(a)). However, this pseudo-gap begins to diminish for the striped $\frac{1}{2}$ ML configuration and higher $1 \mathrm{ML}$ coverage (figure 4(b)). At the same time, projections of $\mathrm{Mg}(3 \mathrm{p}$ ) states were found to be negligible to make any contribution to the interaction in the $\mathrm{Cu} / \mathrm{MgO}(001)$ interface. Our results are close to those of $\mathrm{x}$-ray emission spectroscopy [30] where the gap between magnesia and copper peaks was found to be $\approx 1 \mathrm{eV}$.

The sensitive balance of the attraction and repulsion of polarized $\mathrm{Cu}$ atoms in the vicinity of the substrate defines the distance between a $\mathrm{Cu}$ sub-monolayer plane and the underlying $\mathrm{MgO}$ slab. We found also an increase of in-plane metallic bonding between $\mathrm{Cu}$ adatoms when 
$\mathrm{Cu}$ atomic fraction increases. This leads to a simultaneous decrease of $\mathrm{Cu}$ adatom polarization, which together with a strain-induced repulsion results in a decrease of the physisorption-type bonding. As a consequence, with an increase of the fraction of adatoms the distance between the 2D lattice of $\mathrm{Cu}$ atoms and underlying $\mathrm{MgO}$ slab also increases, while the adhesion energy for $\mathrm{Cu}$ shows the opposite tendency. Our calculations of the adhesion curve show that the process of the metal adatom approaching the oxide surface may be rather unexpected. It may include several (in our case, two) local minima. This means that depending on the temperature and the kinetic energy of the metal atoms, they may be localized at different distances from the substrate surface, thus complicating the morphology of the growing thin metallic film. We produced self-consistent calculations thoroughly enough to be sure in this double-well structure, which is caused by a delicate interplay of the different spin states. (We shall discuss the triplet states of the $\mathrm{Cu} / \mathrm{MgO}$ interface and possible issues of its magnetic behaviour in a separate study.) The existence of a metastable energy profile with several minima could be important for the adsorption theory and for catalytic models. Moreover, a comparison of two different copper adatom configurations, corresponding to the same $\frac{1}{2}$ ML coverage (figures 1(b) and (c)), allows us to predict the tendency to formation of $\mathrm{Cu}$ clusters on $\mathrm{MgO}(001)$ surface.

\section{Thermodynamic analysis of ultra-thin-film growth}

The energy of heterogeneous mixture of the components of the $\mathrm{Cu}-\mathrm{E}$ 'solid solution' (section 2.3) was chosen in a conventional way as the reference state energy [33]. In our case it is calculated as the sum of weighted (with atomic fractions) total energies per lattice site for the 'empty' lattice above the $\mathrm{MgO}(001)$ surface (i.e. pure magnesia substrate) and the lattice filled by $\mathrm{Cu}$ atoms above the same $\mathrm{MgO}$ slab (1 ML). Since for completely ordered states all long-range order parameters are equal to unity, we obtain the formation energies for the $2 \mathrm{D}$ superstructures at different distances $z_{\mathrm{Cu}}$ from the $\mathrm{MgO}(001)$ surface, performing the $B 3 L Y P$ calculations on ordered adsorbate patterns atop the three-layer slab model of magnesia substrate. All these energies are positive, i.e. such ordered phases are unfavourable as compared with the reference state. Thus, decomposition in $2 \mathrm{D} \mathrm{Cu}-\mathrm{E}$ solid solution into two phases with different morphologies should occur even at $T=0 \mathrm{~K}$. When $T$ increases, the spinodal decomposition in the $\mathrm{Cu}-\mathrm{E}$ 'alloy' takes place. To analyse this decomposition, the further thermodynamic study should be carried out.

The condition $n(\mathbf{r})=c_{A}=$ constant corresponds to the case of disordered 2D solid solution. This gives the free energy of the solid solution defined by equation (2):

$$
F(c)=-\frac{1}{2} \tilde{V}(0) \cdot c(1-c)+k T[c \ln c+(1-c) \ln (1-c)],
$$

where $\tilde{V}(0)$ is the Fourier transform of the effective mixing potential defined by equation (1) for the zero wavevector, $\mathbf{k}=\mathbf{0}$. We found that for different structures, which correspond to different atomic fractions of $\mathrm{Cu}$, the equilibrium distance from the $\mathrm{MgO}$ substrate increases from 2.08 to $2.36 \AA$ as the atomic fraction grows from $\frac{1}{4}$ ML to 1 ML. Expressing the values of the internal formation energies $U_{1}, U_{2}$ and $U_{3}$ (section 2.3) for completely ordered structures, we obtain the dependence of the energy parameter $\tilde{V}(0)$ on the interfacial distance, $z_{\mathrm{Cu}}$ (figure $5(\mathrm{a})$ ). This dependence is related to the previously discussed changes in $\mathrm{Cu}-$ $\mathrm{MgO}(001)$ interactions when the number of $\mathrm{Cu}$ atoms on the 2D lattice changes and reflects partly the response of the system to mismatch of the $\mathrm{Cu}$ layer and the $\mathrm{MgO}(001)$-terminated substrate. This dependence may be translated into the dependence of $\tilde{V}(0)$ on the atomic fraction of $\mathrm{Cu}, c$, as displayed in figure 5(b). The latter is almost linear, and is well fitted by the function $\tilde{V}(0)(c)=-0.6858-0.0823 c$. Substituting this result into equation (4) we obtain the asymmetric dependence of the free energy of the disordered $\mathrm{Cu}-\mathrm{E}$ solid solution on the 

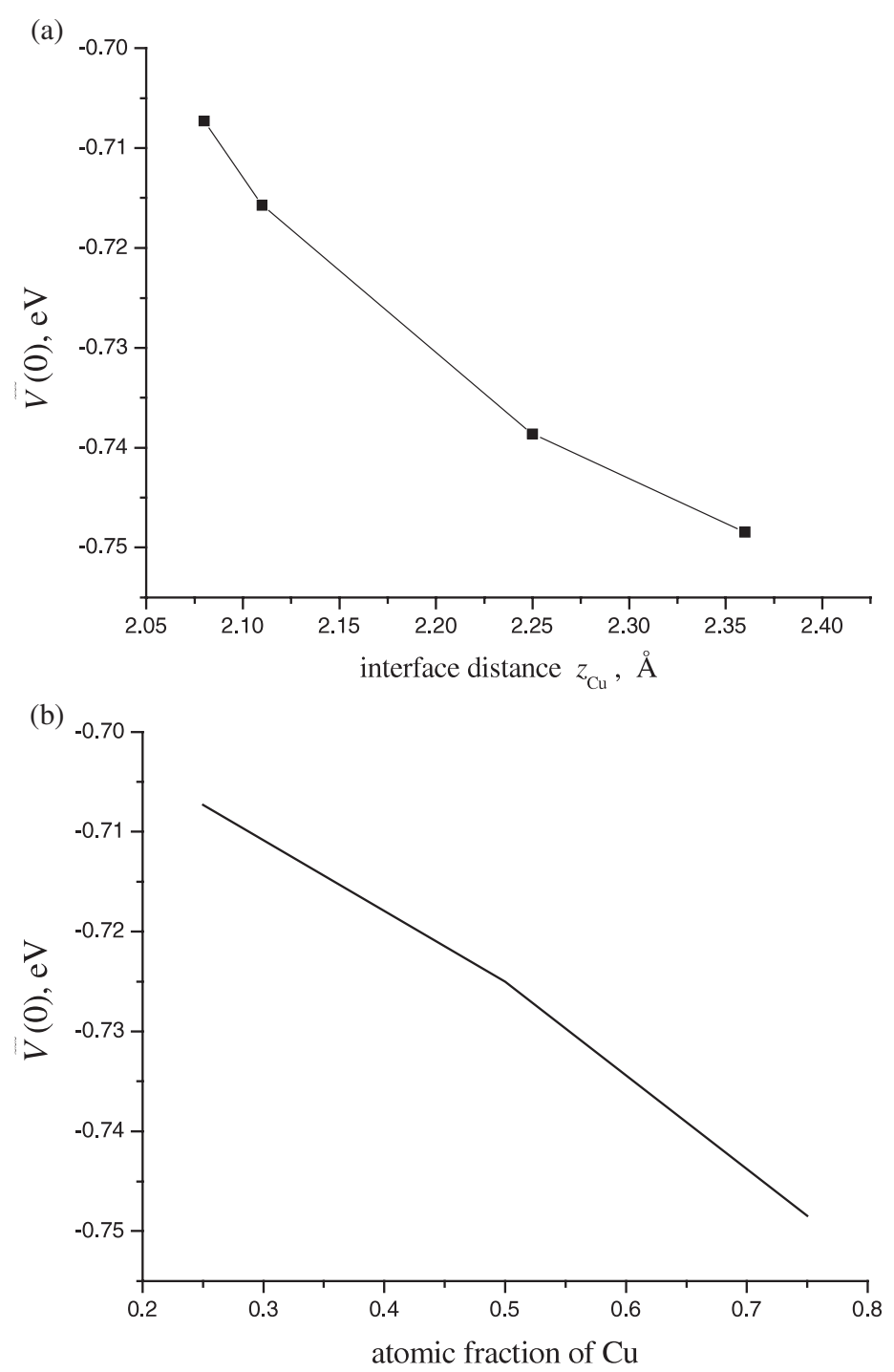

Figure 5. The calculated dependences of the energy parameter $\tilde{V}(0)$ on both the interfacial distance $z_{\mathrm{Cu}}(\mathrm{a})$ and the atomic fraction of $\mathrm{Cu}$ in the layer which was used in the calculations of the phase diagram of the $2 \mathrm{D} \mathrm{Cu}-\mathrm{E}$ solid solution (b).

composition. This result gives the so-called sub-regular solid solution, and the corresponding phase diagrams for the $\mathrm{Cu} / \mathrm{MgO}(001)$ interface with the solubility and spinodal curves are presented in figure 6.

The phase diagram represents the case of the limited solubility in a binary $2 \mathrm{D} \mathrm{Cu}$ atom-'empty site' quasi-particle solid solution. The solvus is shown in figure 6 by the solid curve, whereas the dotted curve shows the spinodal. The solubility curve is determined by the necessary minimum condition, $\mathrm{d} F(c) / \mathrm{d} c=0$, whereas the spinodal curve is given by the equation $\mathrm{d}^{2} F(c) / \mathrm{d} c^{2}=0$. The phase diagram shown in figure 6 (a) finds a pronounced asymmetry of the two-phase region with respect to equiatomic composition, $c=0.5$. This is a direct consequence of the concentration dependence of the energy parameter $\tilde{V}(0)$. The 

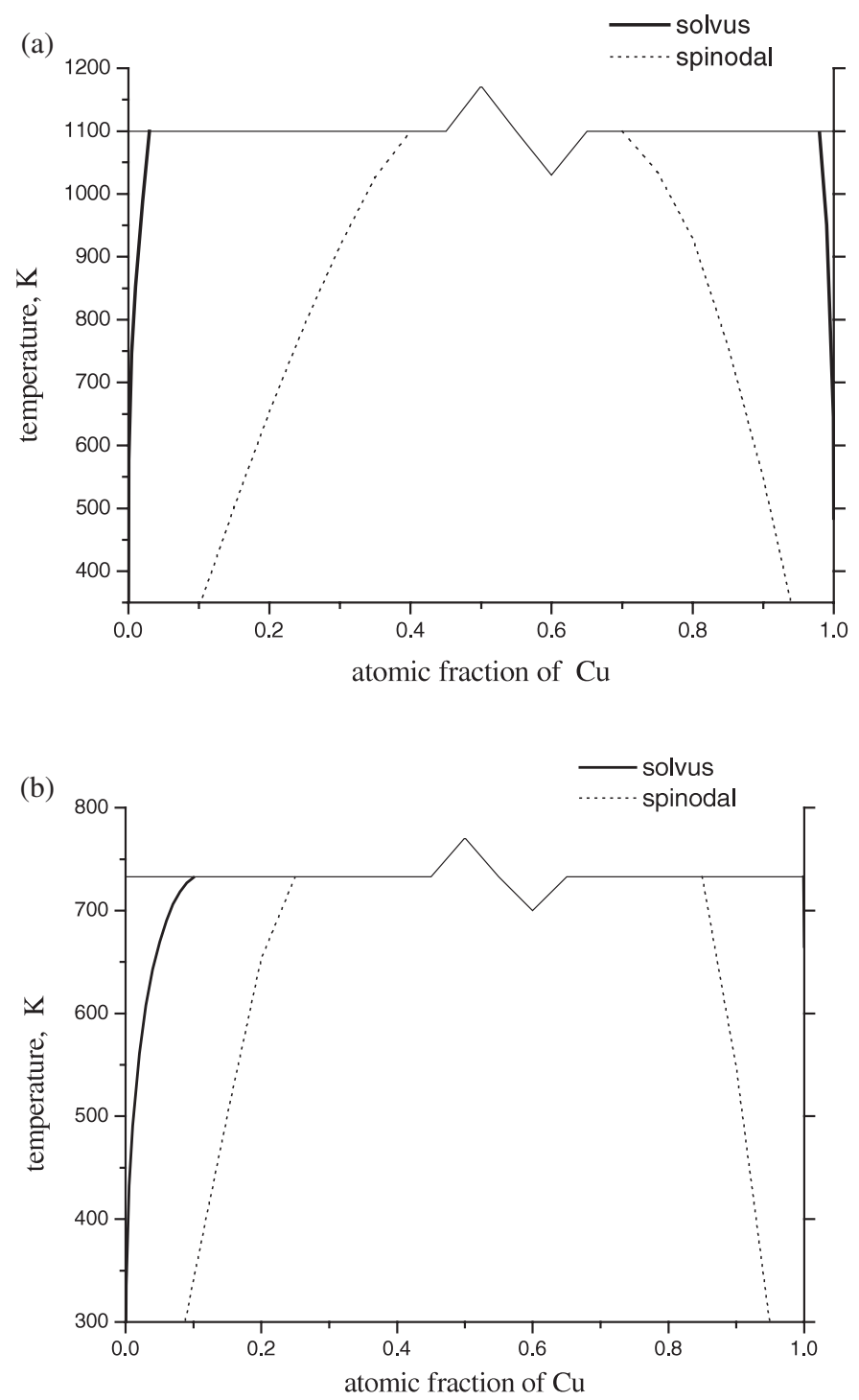

Figure 6. (a) The calculated phase diagram of the $2 \mathrm{D} \mathrm{Cu}-\mathrm{E}$ solid solution. The asymmetric behaviour of the solvus and the spinodal curves with respect to equiatomic composition is clearly seen. This is a result of the concentration dependence of the energy parameter $\tilde{V}(0)$. (b) The same phase diagram as (a) with incorporation of the lattice mismatch effect. For details see text.

decomposition of this solid solution may be analysed in the spirit of our previous study for the $\mathrm{Ag} / \mathrm{MgO}$ interface [11]. As follows from thermodynamic consideration for relatively small amounts of $\mathrm{Cu}$ in the sub-monolayer film, in the region between the solvus and spinodal well separated and compact $\mathrm{Cu}$-rich 2D clusters are expected, while under the temperature and concentration conditions when the system falls below the spinodal, the loose, wormlike morphology of the film should arise. In the particular $\mathrm{Cu} / \mathrm{MgO}$ case this region is rather wide. For example, at $T \approx 1000 \mathrm{~K}$ isolated $2 \mathrm{D} \mathrm{Cu}$ clusters with the local fraction of $\mathrm{Cu}$ atoms $c=0.97$ are formed, whereas the mean concentration of $\mathrm{Cu}$ in the monolayer is varied from 0.02 to 0.3 . 
The existence of the linear term, additionally to the term proportional to $c(1-c)$, in the mixing free energy for solid solutions, as defined by equation (4), is usually associated with accounting for the difference in the layer tensions between pure constituents in A-B solid solution and for the atomic size mismatch [34]. In our case this term appears as the result of the optimization of the distance between the $\mathrm{Cu}$ layer and the $\mathrm{MgO}$ substrate. The dependence of the equilibrium distance $z_{\mathrm{Cu}}$ on $c$ is clearly linked to the changes in the bonding between the underlying $\mathrm{MgO}$ and $\mathrm{Cu}$ atoms in the film, when $\mathrm{Cu}$ atomic fraction in the layer changes. The effect of the mismatch between the $\mathrm{Cu}$ layer and $\mathrm{MgO}$ on the phase diagram is also of great importance. For this purpose, following [34] (see also references therein), we have added the enthalpy term $\Delta H c$ to equation (4), where $\Delta H$ accounts for the atomic size mismatch energy. This value is not well defined and its measurement is also difficult. We have chosen $\Delta H=150 \mathrm{meV}$, assuming that $\Delta H=\left[E_{\mathrm{adh}}\left(c_{\mathrm{Cu}}=1\right)-E_{\mathrm{adh}}\left(c_{\mathrm{Cu}}=\frac{1}{4}\right)\right] / 2$. In other words, we suppose that as the atomic fraction of $\mathrm{Cu}$ in the layer increases from almost separated $\mathrm{Cu}$ atoms in the layer to $1 \mathrm{ML}$ coverage the change in the adhesion energy, $E_{\mathrm{adh}}$, comes in equal fractions from the energy change due to both chemical bonding and the tensile stress caused by mismatch. The values $E_{\text {adh }}$ are taken from our first principles calculations (table 2). Although this is a crude approximation, it permits us to illustrate the effect of mismatch on the topology of the phase diagram as shown in figure 6(b). One can see that accounting for mismatch makes the phase diagram less symmetrical with respect to equiatomic composition $(c=0.5)$ as compared with figure 6(a). At the same time, for conditions discussed in the previous paragraph, the system at room temperature (RT) finds itself still in the two-phase region between the solvus and spinodal, while $\mathrm{Cu}$ clusters, according to the lever rule, will include even fewer empty sites than those predicted from figure 6(a) (no mismatch). Actually, in this case the solubility curve for large atomic fractions of $\mathrm{Cu}$ is very close to the $y$-axis. That is, accounting for mismatch, on the one hand, does not change the general conclusion about the formation of almost perfect, well separated $\mathrm{Cu}$ clusters in the sub-monolayer deposition. On the other hand, the mismatch may be decreased sufficiently by the formation of the misfit dislocations at the interface between the substrate and the film.

Continuing to explore the idea of the $\mathrm{Cu}-\mathrm{E}$ solid solution, it is also possible to understand qualitatively the formation of $\mathrm{Cu}$ clusters or even $3 \mathrm{D} \mathrm{Cu}$ islands in a somewhat different way. Let us assume the existence of a 3D Cu-'empty site' quasi-particle solid solution on the Ising lattice. The sites of such a 3D lattice are situated above oxygen atoms, and the lattice is immersed in the field of the electronic charge distribution created by the magnesia surface just as it was in the 2D case. The lattice sites of this 3D lattice are partly occupied by $\mathrm{Cu}$ atoms. Thus, we have a system that contains a half-infinite $\mathrm{MgO}(001)$ and a half-infinite $\mathrm{Cu}-\mathrm{E}$ separated by the distance $z_{\mathrm{Cu}}$. The formation of $2 \mathrm{D}$ clusters discussed above may be considered as the segregations of $\mathrm{Cu}$ onto the first plane of such a lattice, which lies at the distance $z_{\mathrm{Cu}}$ from $\mathrm{MgO}(001)$. These 2D segregations may serve as the nuclei of $\mathrm{Cu}$ islands. When additional $\mathrm{Cu}$ atoms beyond the $1 \mathrm{ML}$ regime are deposited on $\mathrm{MgO}$, they are attached to the already existing $2 \mathrm{D}$ clusters and the formation of the $3 \mathrm{D}$ islands occurs, with the height of several layers at the surface of the semi-infinite $\mathrm{Cu}-\mathrm{E}$ lattice. This means that the formation of $3 \mathrm{D} \mathrm{Cu}$ clusters could be considered as $\mathrm{Cu}$ segregation on the surface of the $\mathrm{Cu}-\mathrm{E}$ solid solution.

The identity of the thermodynamic approaches in the study of segregation and adsorption at the interface is discussed in [35]. It is well known that in the case when the surface segregation of component A on the surface of an A-B alloy occurs the concentration profile of surface segregation for this component decreases from the surface into the bulk [36]. It may decrease from rather large values, close to unity, to the average atomic fraction of component $\mathrm{A}$ in the bulk. For our $\mathrm{Cu}-\mathrm{E}$ solid solution this means decreasing number of $\mathrm{Cu}$ atoms in successive 
planes in the direction from the $\mathrm{MgO}$ surface. That is, when the growth of the second $\mathrm{Cu}$ layer in the island occurs above the already existing $2 \mathrm{D}$ cluster in the first plane, the number of $\mathrm{Cu}$ atoms in the layer second from the surface is smaller. The same occurs for the third, fourth etc layers and thus leads to the formation of 3D $\mathrm{Cu}$ islands having specific geometric structurethe higher the layer from the basis of the island, the smaller the effective area occupied by $\mathrm{Cu}$ atoms. Indeed, if the atomic fractions, $c_{p}$, in each layer, $p$, inside the island were the same, it is easy to estimate that the area of the layer $(p+n)$ in the island should satisfy the condition $S_{p+n} / S_{p}=\bar{c}_{p+n} / c_{p}$, where $S_{p+n}$ and $S_{p}$ are the areas of layers $(p+n)$ and $p$ inside the 3D island, and $\bar{c}_{p+n}$ is the averaged atomic fraction of $\mathrm{Cu}$ in the $(p+n)$ th layer from the $\mathrm{MgO}$ surface. Then, at the top of such a 3D Cu island we may have the area that includes the number of sites that with respect to the total number of sites in the basic layer of island equals $\bar{c} / c_{0}$, where $\bar{c}$ is the average fraction of $\mathrm{Cu}$ atoms in $\mathrm{Cu}-\mathrm{E} 3 \mathrm{D}$ solid solution and $c_{0}$ is the fraction of $\mathrm{Cu}$ atoms in the basis layer of the island. Thus, the height of the islands in some sense is defined by the shape of the concentration profile for the surface segregation in $\mathrm{Cu}-\mathrm{E} 3 \mathrm{D}$ solid solution. In principle, it is also possible to restore the shape of the $3 \mathrm{D}$ island.

In the framework of this model it is also possible to estimate the surface segregation energy, $E_{\text {segr }}$, for $\mathrm{Cu}$ islands on $\mathrm{MgO}(001)$, using the phase diagram in figure 6(a). By definition, the surface segregation energy is the energy cost of transferring one impurity atom from the bulk of a host crystal to its surface and thus may be calculated as the difference in the total energy of the system with the impurity in a surface layer and in the bulk. In the case when the ordering effects at the surface are absent (our case of the $\mathrm{Cu}-\mathrm{E}$ solid solution), it was shown [36] that the Langmuir-McLean relation

$$
E_{\mathrm{segr}}=k T \ln \frac{\bar{c}\left(1-c_{\text {surf }}\right)}{c_{\text {surf }}(1-\bar{c})}
$$

holds quite well. Using this relation, we estimate at $T=300 \mathrm{~K}$ and $\bar{c}=0.3$ that $E_{\text {segr }}=-0.416 \mathrm{eV}$. This may serve as an additional confirmation of our statement that the formation of $\mathrm{Cu}$ islands on the ideal $\mathrm{MgO}(001)$ surface in normal conditions is almost unavoidable.

\section{Summary}

For a comprehensive study of the perfect $\mathrm{Cu} / \mathrm{MgO}(001)$ interface, we have combined here first principles DFT GGA-LCGTF slab calculations with the thermodynamic formalism, which permits us to construct the phase diagram of the $\mathrm{Cu}$-'empty site' quasi-particle solid solution. One of the general conclusions is that there is no $\mathrm{Cu}$ chemisorption or strong ionic bonding on the defectless non-polar (001) magnesia surface. For all considered coverages, the position of the polarized $\mathrm{Cu}$ adatom atop the surface $\mathrm{O}^{2-}$ ion is the energetically preferable over that atop $\mathrm{Mg}^{2+}$. For the isolated $\mathrm{Cu}$ adatom, $E_{\text {adh }}=0.62 \mathrm{eV}$ and $z_{\mathrm{Cu}}=2.08 \AA$. The sensitive balance of the attraction and repulsion of polarized $\mathrm{Cu}$ atoms in the vicinity of the substrate affects the equilibrium distance between the $\mathrm{Cu}$ plane and the $\mathrm{MgO}$ slab. An increase of in-plane metallic bonding between $\mathrm{Cu}$ adatoms as the atomic fraction increases leads to a simultaneous decrease of polarization of $\mathrm{Cu}$ adatoms and of the physisorption-type binding energy.

The phase diagram for the $\mathrm{Cu}$ - 'empty site' lattice predicts the decomposition of the solid solution into the two disordered phases. One of these phases is very rich in $\mathrm{Cu}$ atoms (compact and dense $\mathrm{Cu}$ clusters), while the second one is highly impoverished by them (almost empty lattice). The diagram has very narrow solubility limits and a wide asymmetric region between the solvus and spinodal. For low $\mathrm{Cu}$ coverage, this means that the formation of well separated $2 \mathrm{D} \mathrm{Cu}$ clusters is almost unavoidable at the very initial stages of the $\mathrm{Cu}$ film growth on the 
$\mathrm{MgO}(001)$ substrate, in agreement with experiment [12]. Further formation of 3D Cu islands may be considered in terms of $\mathrm{Cu}$ segregation onto the first $\mathrm{Cu}$ plane at the distance $z_{\mathrm{Cu}}$ above the $\mathrm{MgO}(001)$. We estimated the segregation energy for $\mathrm{Cu}$ clusters growing on $\mathrm{MgO}$ as $E_{\text {segr }}=-0.416 \mathrm{eV}$ at $300 \mathrm{~K}$.

During the film growth due to $\mathrm{Cu}$ deposition from the gaseous phase at RT and atmospheric pressure, the surface density of adatoms in a gas phase is $\sim 10^{13}$ atoms $\mathrm{cm}^{-2}$ whereas the density of all $\mathrm{O}$ sites on the perfect $\mathrm{MgO}(001)$ substrate is $\sim 10^{15}$ sites $\mathrm{cm}^{-2}$. Thus, the real atomic fraction of adatoms in the first $\mathrm{Cu}$ layer is about $1 \%$. As follows from figure 6(a), we expect at RT well separated $\mathrm{Cu}$ clusters with very high (close to unity) atomic fraction of $\mathrm{Cu}$. The question arises of what could be done to manufacture more-or-less homogeneous ultra-thin $\mathrm{Cu}$ film on the $\mathrm{MgO}$ substrate. The solution may be straightforward: we have to change the phase equilibrium conditions in the system, either by changing the external thermodynamic conditions (temperature, pressure) or by changing the fine interactions between $\mathrm{Cu}$ atoms in the field of the underlying $\mathrm{MgO}$ substrate. The latter may be done under special treatment of the $\mathrm{MgO}$ substrate, either by formation of surface F-centres (oxygen vacancy with two electrons) or by its saturation with some impurities before deposition of $\mathrm{Cu}$ atoms. This may turn out to be a quite far-sighted way to improve the quality of deposited metallic film. At the same time, increase of the temperature during the manufacturing of copper film over magnesia (aimed to form a single-phase disordered solid solution above the solvus) can hardly help because of the very small adhesion energy of $\mathrm{Cu}$ film on the substrate. The high-pressure processing of this film may help to create a more uniform $\mathrm{Cu}$ layer since the external pressure applied to the system may increase the solubility (considering the phase diagram with limited solubility of components), thus lowering the solvus curve and enforcing the formation of the disordered $\mathrm{Cu}-\mathrm{E}$ solid solution. At the same time the necessary pressure may be rather high.

Recent achievements in microelectronics and other high technologies demonstrate a growing necessity in improving and further developing copper applications [37]. One of the most pressing issues is an increasing demand for epitaxially grown $\mathrm{Cu}$ films on non-conducting substrates and fabrication of smooth copper films, to serve as a growth template for device structures, such as tunnelling magneto-resistance devices [38]. In this sense $\mathrm{Cu}$ is an example of the first series transition metals used as magnetic layers. Further theoretical studies of the morphology of a $\mathrm{Cu}$ layer on $\mathrm{MgO}$, thermodynamics of thin-film/3D cluster growth, their magnetic properties and adhesion on surface defects and on a modified $\mathrm{MgO}$ surface with a seed metal layer [39] are of great interest.

\section{Acknowledgments}

This study was partly supported by the European Centre of Excellence for Advanced Materials Research and Technology (Riga, Latvia, contract No ICA1-CT-2000-7007 to YZ and EK), by Mittel des Promotionsprogramms in Universität Osnabrück (YZ) and by the German-Israeli Foundation (GIF) (grant No G-703-41.10/2001 to EK and SD). The authors kindly thank K Doll, E Heifets, F Illas and J Maier for valuable discussions as well as O Sychev for technical assistance.

\section{References}

[1] Santra A K and Goodman D W 2003 J. Phys.: Condens. Matter 15 R31

[2] Stoneham A M and Tasker P W 1985 J. Phys. C: Solid State Phys. 18 L543

[3] Yang X J and Perry S S 2002 Surf. Sci. 506 L261

[4] Bacalis N C and Kunz A B 1985 Phys. Rev. B 324857 
[5] Li Y, Langreth D C and Pederson M R 1995 Phys. Rev. B 526067

[6] Pacchioni G and Rösch N 1996 J. Chem. Phys. 1047329 Lopez N, Illas F, Rösch N and Pacchioni G 1999 J. Chem. Phys. 1104873 Pacchioni G 2003 Surf. Sci. 5203

[7] Matveev A V, Neyman K M, Yudanov I V and Rösch N 1999 Surf. Sci. 426123

[8] Geudtner G, Jug K and Köster A M 2000 Surf. Sci. 46798

[9] Musolino V, Selloni A and Car R 1998 J. Chem. Phys. 1085044 Musolino V, Selloni A and Car R 1999 Phys. Rev. Lett. 833242

[10] Benedek R, Minkoff M and Yang L H 1996 Phys. Rev. B 547697 Benedek R, Seidman D N, Minkoff M, Yang L H and Alavi A 1999 Phys. Rev. B 6016094

[11] Fuks D, Dorfman S, Kotomin E A, Zhukovskii Yu F and Stoneham A M 2000 Phys. Rev. Lett. 854333 Fuks D, Dorfman S, Zhukovskii Yu F, Kotomin E A and Stoneham A M 2002 Surf. Sci. 49924

[12] Zhou J B and Gustafsson T 1997 Surf. Sci. 375221

[13] Saunders V R, Dovesi R, Roetti C, Causá M, Harrison N M, Orlando R and Zicovich-Wilson C M 1999 CRYSTAL'98 User Manual University of Turin

[14] Gomes J R B, Illas F, Cruz Hernández N, Fernández Sanz J, Wander A and Harrison N M 2002 J. Chem. Phys. 1161684

[15] Becke A D 1993 J. Chem. Phys. 985648

[16] McCarthy M I and Harrison N M 1994 Phys. Rev. B 498574

[17] Cappellini G, Bouette-Russo S, Amadon B, Noguera C and Finocchi F 2000 J. Phys.: Condens. Matter 123671

[18] Roessler D M and Walker W C 1967 Phys. Rev. 159733

[19] Doll K and Harrison N M 2000 Chem. Phys. Lett. 317282

[20] Zhukovskii Yu F, Gryaznov D, Finogenov A and Shunin Yu N 2001 Comput. Model. New Technol. 528

[21] Hay P J and Wadt W R 1985 J. Chem. Phys. 82284

[22] Zhukovskii Yu F, Kotomin E A, Jacobs P W M and Stoneham A M 2000 Phys. Rev. Lett. 841256 Zhukovskii Yu F, Kotomin E A, Dorfman S, Fuks D and Gordon A 2001 Surf. Sci. 482-485 66

[23] Heifets E, Eglitis R I, Kotomin E A, Maier J and Borstel G 2001 Phys. Rev. B 64235417

[24] Press W H, Teukolsky S A, Vetterling W T and Flannery B P 1997 Numerical Recipes in Fortran 77 (Cambridge, MA: University Press)

[25] Jepsen O, Glötzel D and Mackintosh A R 1981 Phys. Rev. B 232684

[26] Foiles S M, Baskes M I and Daw M S 1986 Phys. Rev. B 337983

[27] Herschend B, Hermansson K, Alfredsson M, Zhukovskii Yu F, Kotomin E A and Jacobs P W M 2003 J. Phys. Chem. B 10711893

[28] Causá M, Dovesi R, Pisani C and Roetti C 1986 Surf. Sci. 175551

[29] Colonna S, Arciprete F, Balzarotti A, Fanfoni M, De Crescenzi M and Mobilio S 2002 Surf. Sci. 512 L341

[30] Jonnard P and Bonnelle C 1999 Surf. Sci. 436 L724

[31] Larsen J H, Starr D E and Campbell C T 2001 J. Chem. Thermodyn. 33333

[32] Khachaturyan A G 1983 Theory of Structural Transformations in Solids (New York: Wiley)

[33] Kaufman L and Bernstein H 1970 Computer Calculations of Phase Diagrams (New York: Academic)

[34] Polak M and Rubinovich L 2000 Surf. Sci. Rep. 38127

[35] Umantsev A 2001 Phys. Rev. B 64075419

[36] Ruban A V and Skriver H L 1999 Comput. Mater. Sci. 15119

[37] Murarka S M, Verner I V and Gitmann R J 2000 Copper-Fundamental Mechanisms for Microelectronic Applications (New York: Wiley)

[38] Siemroth P and Schülke T 2000 Surf. Coat. Technol. 133/134 106

[39] Mewes T, Rickart M, Mougin A, Demokritov S O, Fassbender J, Hillebrands B and Scheib M 2001 Surf. Sci. 48187 